\title{
THOUGHTFUL APPROACHES TO IMPLEMENTATION OF ELECTRONIC RULEMAKING
}

\author{
Dr. T. G. K. Vasista \\ E-Governance Consultant, India,
}

\section{ABSTRACT}

The Internet could fundamentally change the way that both government and public participates in making public policy but changes must be made in our existing civic infrastructure for that. The change in the law causes modifications in the policies/strategies in which this law has been implemented. This paper focuses on approaches to thoughtful implementation of electronic rulemaking could capture public interest, particularly in higher profile rulemakings and how online forums and dialogues can foster greater public participation in making public policy processes at the centre as well as presenting the need of semantic perspectives and semantic web technology to enhance the inference capability and to provide decision making capability.

\section{KEYWORDS}

Electronic Rule Making, Meta-Models, Public Bill Process Automaton, Public Service Delivery Model Ontology, Semantic web intelligence

\section{INTRODUCTION}

The Internet could fundamentally change how the public participates in making public policy but changes must be made in our existing civic infrastructure [12]. In particular, for the purpose of building the support of designing or modifying a public policy, the central government should build a transparent online environment that encourages public input. Such an effort should include two simple innovations: online policy dialogues [10], forums [27] and electronic public classifiers [34]. These mechanisms would allow groups and individuals from across the nation to have a greater say in how government develops new policies and regulations.

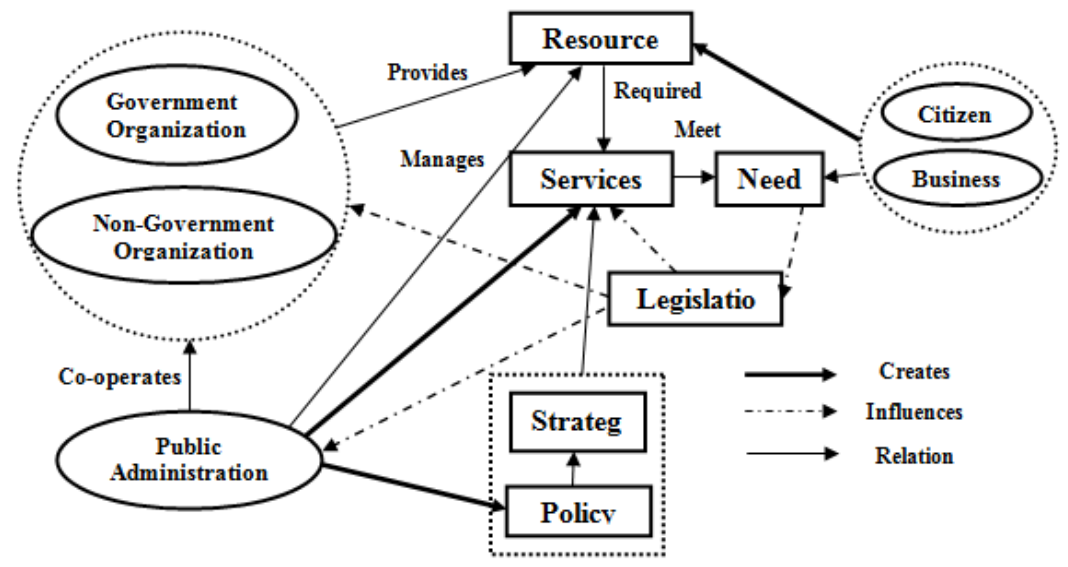

Fig. 1. Government Service - Supply scenario model [24] (Redrawn) 


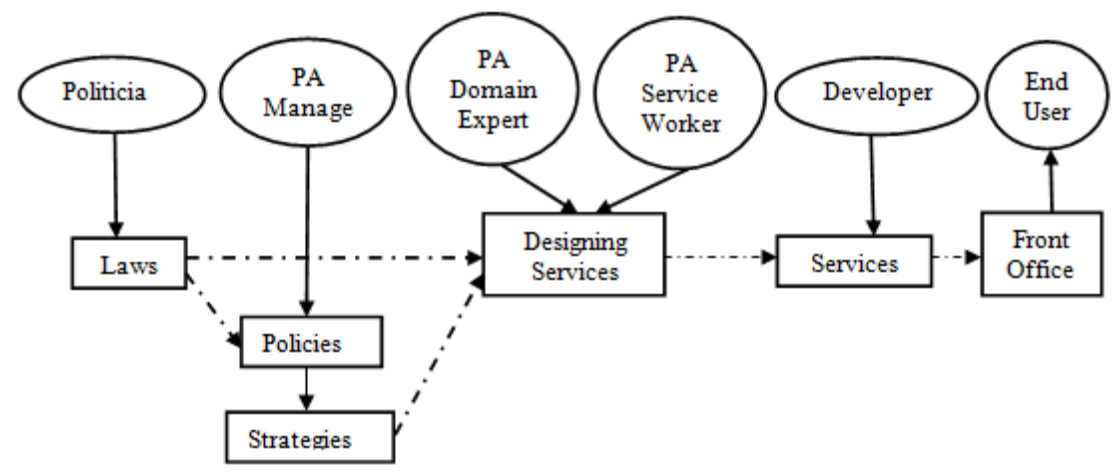

Fig 2. Roles involved in Public services delivery model [24] (Redrawn)

Due to the changes in the political goals of a government (this may be due to the influence of international domestic market conditions or may be cultural changes of the citizens), changes in the environment, or changes in the needs of the people, the politicians might make the revision of a law. The change in the law causes a modification in the policies/strategies in which this law has been implemented. Domain expert must understand the changes and reconfigure the service description as per the modifications of public policy in view of protecting the e-service consumers [28], for e.g. privacy policy [46]. So information systems need to support internal work within a government's boundaries, service customers through digital interfaces and leverage digital relationships among social partners [38].

The following section provides steps in the life cycle process of formulating a public bill.

\section{Formulation of Public biLl}

Law-making is a form of the state activity intended on the creation of the Legal norms. The Lawmaking is a process during which an idea of Law is transformed into a Law. The forms of Law include: acts of the Legislative bodies called statutes, acts of the executive body called orders, instructions etc. and at last judicial precedents called legal customs. When a government body has to take an official decision, it gives the task to various committees, departments to write a bill and its correspondence of a possible act to the current legislation and to the constitution. The government introduces greater part of bills and controls the legislative process to a greater or less degree. The law making process begins out of the legislative bodies. A bill passes a long way and is changed several times before introducing into the legislative body. Either the political party or the governmental bodies may initiate the law-making process by drafting and initiating a bill [11]. The bills are drafted by a team of lawyers in the parliamentary counsel office, which is a part of the cabinet office based on the instruction of the concerned government department. The bill could pass through standing committees and to both lower house and upper house of parliament and may travel backward and forward between two houses for having thorough discussions when conflicts arise. When agreed by both houses, the bill is submitted to the President's office to get the assent of the President (at the state level it is from the Governor who acts as an agent to the President) [25]. For example, the outline of the life cycle of legislation for the California State Assembly is given in passing [7]. Figure 3 and Table 1 shows the life cycle of public bill and its process in brief and in detail respectively. 


\subsection{Life Cycle of Public Bill}

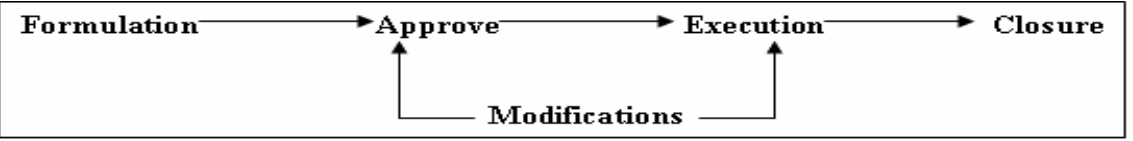

Fig. 3. Life Cycle of a public bill [13]

\subsection{Detailed Steps for the Process of Life Cycle of a Public Bill}

Steps of Life cycle of a bill have been presented in a tabular format as show in Table 1 .

Table 1. Steps of life cycle of a bill

\begin{tabular}{|c|c|}
\hline $\begin{array}{l}\text { 1. To prepare preliminary public } \\
\text { policy draft }\end{array}$ & $\begin{array}{l}\text { 6. To elaborate new public policy } \\
\text { according to constitution }\end{array}$ \\
\hline 2. To define public policy & $\begin{array}{l}\text { 7. To distribute in parliament/assembly } \\
\text { for suggestions and modifications }\end{array}$ \\
\hline 3. To formulate public policy draft & $\begin{array}{l}\text { 8. To elaborate public policy } \\
\text { Modifications }\end{array}$ \\
\hline $\begin{array}{l}\text { 4. To present public policy draft to } \\
\text { Legislature }\end{array}$ & $\begin{array}{l}\text { 9. To submit to president/governor to } \\
\text { get assent on the public policy bill }\end{array}$ \\
\hline $\begin{array}{l}\text { 5. To approve public policy in } \\
\text { Legislature }\end{array}$ & $\begin{array}{l}\text { 10. To publish in the gazette and to } \\
\text { give the legal status }\end{array}$ \\
\hline
\end{tabular}

There are two situations where the availability of semantic information associated to public policy is critical: public policy formulation and approval tasks. In first case, only government staff with specific knowledge can be involved in this task, concentrating a high responsibility in few persons with much difficult to knowledge transference. In second case, for semantics information it is necessary to analyze public requirements data and then to make it to a law. Here, it is more complex because all the legislators must vote and the majority may not have the specific knowledge [13].

So developing and maintaining e-Government services that can effectively deal with changes is a challenge for public administration. Such a synthesis of systematic response to changes with knowledge to deal with then has a positive impact on change management process. So the decision making regarding public policy modifications can be achieved by systematically applying elementary and composite ontology changes [6] and by adopting semantic web services technology.

\section{NeEd FOR CONSIDERING SemantiC INFORMation in PUblic SERViCES 3.1. The Semantic Web}

At its core, the semantic web comprises a set of design principles, collaborative working groups, and a variety of enabling technologies. The elements of the semantic web are expressed in formal specifications. Some of these include Resource Description Framework (RDF), a variety of data interchange formats (e.g. RDF/XML, N3, Turtle, N-Triples), and notations such as RDF Schema (RDFS) and the Web Ontology Language (OWL), all of which are intended to provide a formal description of concepts, terms, and relationships within a given knowledge domain [5]. 


\subsection{Use of ontology and meta-models in Public Services Delivery}

Stojanovic et al. (2004) [39] elucidated the use of ontology and meta-models in the public service delivery while working for the OntoGov Project of USA.

Ontologies are a formal explicit specification of a shared conceptualization. In the E-Government domain they may be used not only for describing and composing services provided by governments and administrations, but also for modelling dependencies between decisions of the different stakeholders (e.g. politicians, public managers and software developers) in order to make services easier for the development and cheaper for the maintenance [39:1].

An ontology description involves the description of domain specific terminology and the ontology defining meta-concepts connected to the description of involved services. Ontology and meta-data management provides the capabilities of modularization, rule specification, lexical analysis, efficient reasoning, dealing with compliance and standards, support of having web services modelling using semantic web services modelling (e.g. WSMO). However, it is important here to check whether and with which degree the ontological framework and its infrastructures provide support for modelling of web services [36] [13].

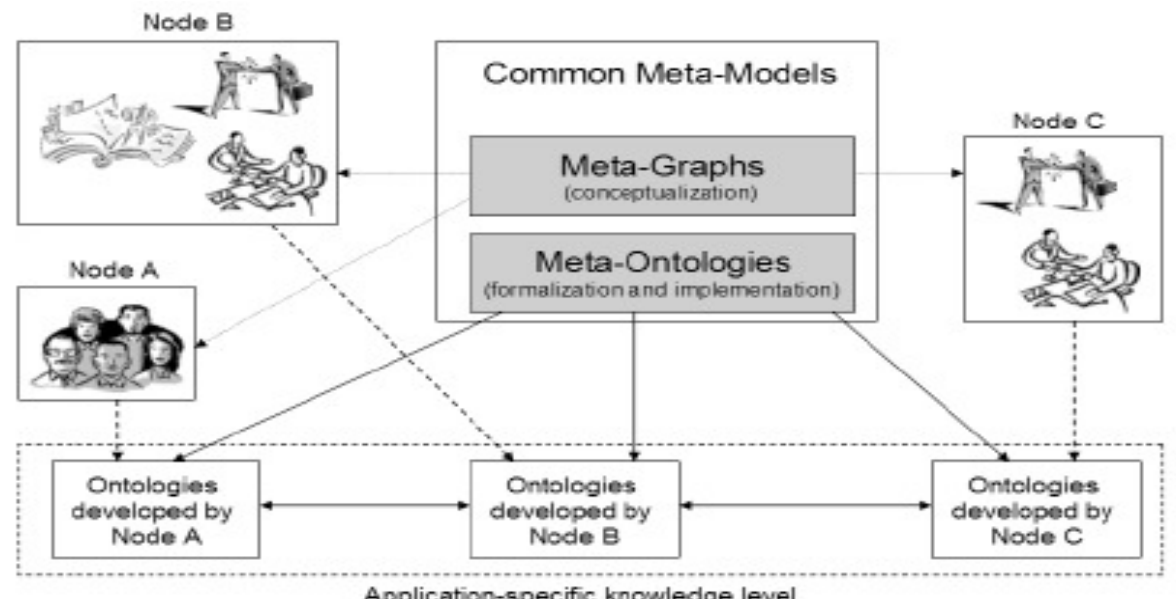

Fig. 4. Use of ontology and meta models in Public Services Deliver [13]

Ontology can reuse modules from other ontologies through modularisation. Module inclusion might be supported by allowing ontology to include other ontologies, thus obtaining the union of the definitions from all included models. All definitions from an included ontology are automatically available in the including ontology [39:18].

The configuration process requires the selection of the appropriate modules and then their customisation and integration according to the specific needs of the scenario allowing representations at different levels of granularity [39:26].

While AlSudairi and Vasista (2013) [3] proposed 'ASCP' Model as a strategic driving methodology towards facilitating the level of conceptualization and granularity for treating the domain ontology, where the standardization of ASCP model can be mapped to as constitution based public policy, Bargui et al. (2011) [9] proposed four steps for decision making ontology building process viz. (i) enrichment (ii) extraction (iii) comparison and (iv) upgrade that can 
generate the decision making knowledge as a standard concept and to construct the decision making ontology in the form of building a public policy that can go for the president assent.

For example, Weblogs and message boards provide online forums for discussion that records the voice of the public that has a wide range of opinion and commentary about consumer products, where the possible types of e-participation include: Citizens, citizen representatives, business community, Political parties, civic activities and the government itself [35].

Administrative intelligence can be derived through an interactive analysis framework uniquely configured to leverage the connectivity and content of annotated online discussion. In short, an approach to build a mature system which leverages online data to help make informed and timely decisions with respect to political parties, services and strategies in the cabinet and stateassembly work space for public policy can be described. The system processes of online content for entities interested in tracking the opinion of the online public (often as a proxy for the general public). It is an approach that built on technology solutions which use comprehensive crawling, text mining, classification and other data driven methods to describe the opinion reported in online data [23].

Apostolou et al. (2011) [6] have illustrated an approach for the adaptation of e-Government services to changes in legislation, business requirements, users' needs etc. as well as the consistent propagation of these changes to dependent artifacts that are implemented using web service technologies. It is a three-layer model that takes into account ontologies such as: Domain ontology, legal ontology, organizational ontology the profile ontology and the life cycle ontology. Finally, the service evolution and the web service orchestration registry ontologies are used for tracking changes in the e-government service and for the deployment and execution of the service, respectively.

\subsection{Legal Visualization}

Usually in the legislation formulation stage, the existing legal framework has to be taken into account. It normally consists of several interconnected legal structures (e.g. local laws, presidential decrees and directives etc.). Therefore it is useful to provide a visualization of the existing legal frameworks, which can be based on relevant ontologies, such as the legal framework ontology [30]. The powerful combination of the linguistic and statistical analysis of the text documents (that containing discussions and arguments) provide useful ideas contributing to the public policy making using these novel visualization techniques and efficient toolset for advanced visualization of messages posted in an online environment. It also support monitoring and analysis of e-participation [42].

\section{Role OF META-DATa IN ONLINE RULEMAKING}

Public sector metadata promises to be a key enabler of the Semantic Web. Government metadata implementations should therefore consider the potential benefits of compliance with Semantic Web protocols such as RDF and OWL. Governments need metadata to manage, understand, enable access to, and preserve their vital data assets over time and across domains of use. Metadata documents the content, context and structure of information resources in order to support the ongoing use of those resources [18].

In a networked world where 'joined up Government' is an imperative, metadata usually needs to be able to be shared/exchanged and reused by different entities for different purposes, usually by automated systems. Because, machines need predictability to successfully process metadata (i.e. in order to become interoperable). Inadequate metadata may result in the failure to locate and/or share important information when it is needed because of a lack of adequate descriptive 
metadata. So it is not possible to read/use digital information due a lack of technical metadata about the structure and technical properties of the digital information object. It is also not possible to attribute meaning or value to information due to a lack of contextual metadata and finally verifying the authenticity and reliability of information becomes an issue [18].

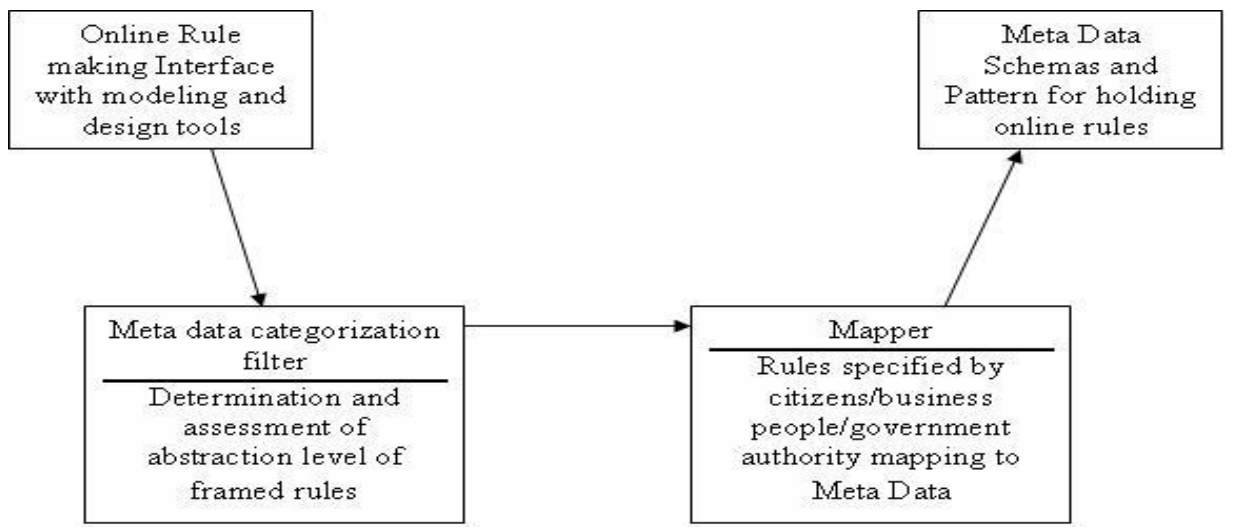

Fig. 5. Role of Metadata in Online Rule Making

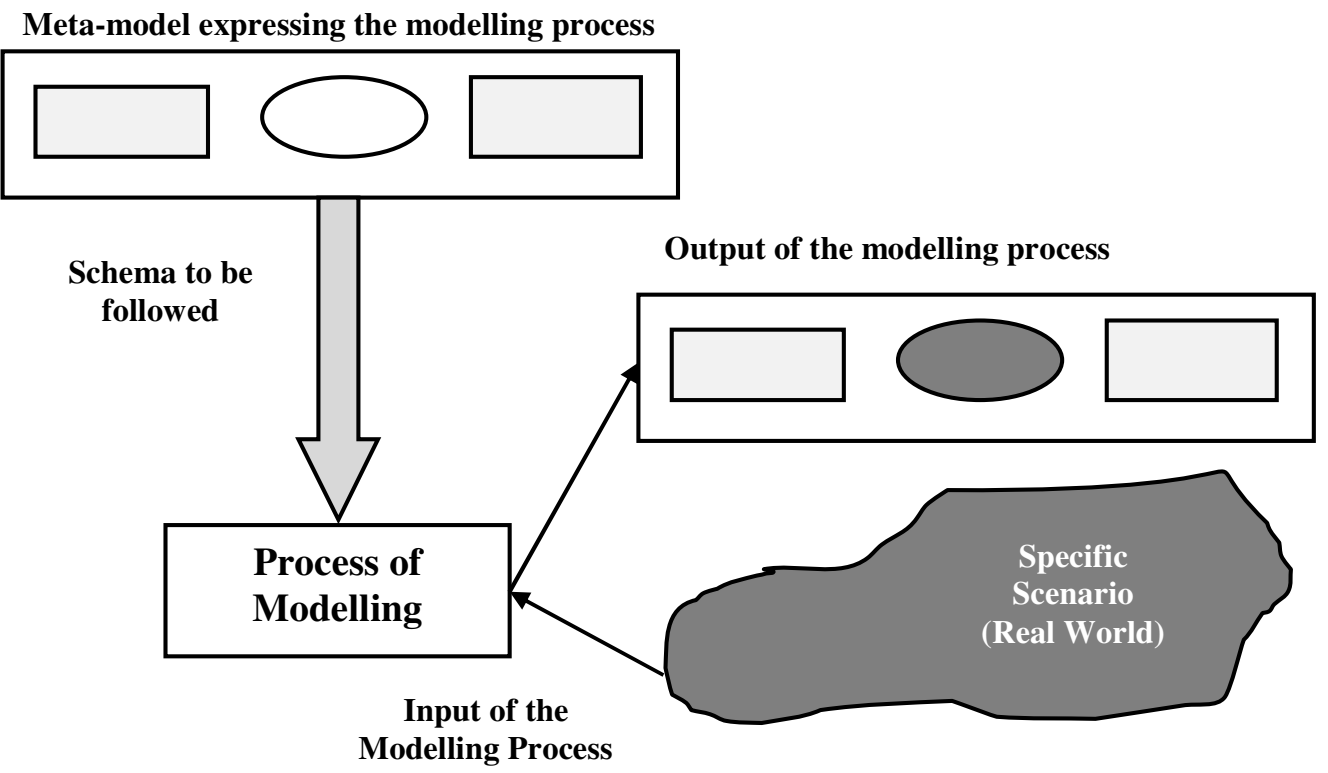

Fig 6. Meta-Model expressing the modelling process: A customization process through instantiation technique.

Uses of metadata in public administrative information system include the following [OR, 7] [18]: Data management (e.g. for statistical data sets); Resource discovery (e.g. standardized descriptions of government online resources and e-government services); Recordkeeping Managing and enabling the use of geospatial data sets; Privacy protection; Information rights management (e.g. for intellectual property management and security management); digital preservation (i.e. ensuring the longevity and continuity of vital data assets); documenting the levels of compliance of information resources with World Wide Web Consortium accessibility standards. 
It is important for metadata regimes to comply with accepted industry standards. Metadata standards standardise one or more of three main aspects of metadata: (i) Structure (how the metadata is structured - often into elements of information or 'properties' consistent with an explicit data model or ontology); (ii) Semantics (what the metadata elements or properties mean); and (iii) Syntax (how the metadata is written/expressed/encoded using common mark-up languages such as HTML and XML and data values consistent with designated controlled vocabularies and encoding schemes) [OR, 3].

\subsection{Some important metadata standards used in public administration}

ISO/IEC 11179 - Metadata Registry Standard; ISO 15836; ISO 19115 - Geographic Information - Metadata; ISO 23081 - Metadata for Records - Conceptual and Implementation Issues; ISO 8601 - a standard for encoding date and time information; PREMIS - Preservation Metadata Implementation Strategies (2005); METS - Metadata Encoding and Transmission Standard; SCORM - Sharable Content Object Reference Model (for e-learning); RDF - Resource Description Framework (a family of World Wide Web [37].

Consortium (W3C) specifications; MODS - Metadata Object Description Schema (US Library of Congress); SOAP - Simple Object Access Protocol (not an acronym any more); OAI - Open Archives Initiative (metadata harvesting protocol).

As a general rule the technical infrastructure supporting metadata implementation should rely on flexible rather than hard-wired enterprise architectures [17]. Service Oriented Architecture (SOA), for example, promises to provide an ideal approach to implementing flexible, dynamic, interoperable and reusable metadata. WSMO for example provide platform independent ontology based semantic web services [44].

\subsection{Profile Management}

A profile, or digital identity, is commonly considered as the machine readable representation of a human identity, with the degree of accuracy required by the type of application. The purpose of a digital identity is to tie a particular transaction or a set of data in e-governance to an identifiable individual/citizen [45].

\subsection{Public Classifier}

The main goal of this section is to investigate techniques that implicitly build ontology-based user/public/citizen profiles.

A key feature in developing successful personalized Web applications is to build user profiles that accurately represent topic of agenda for online discussion. Research work by [41] explains how e-participant profile accuracy can be built by improve based on ontology as follows: Profile can be built without user interaction by automatically monitoring the profile stability, identifying the most important concepts, the effect of depth in the concept-hierarchy on the importance of a concept, and abstraction levels of the subject that the user touched.

Profile ranking is to be done based on various findings that are needed to be done based on the concepts in the profiles by length of the time the citizen has participated in the discussion, depth of the knowledge on the concept-hierarchy according to importance of a concept, and its abstraction levels by accumulated weights so as to achieve better profile accuracy [41]. 


\section{Discussions \& CONCLUSIONS}

Contrary to the conventional view, administrative discretion appears necessary. It is highly desirable in some cases on utilitarian grounds. Legislatures rarely have time to quickly make decisions on governing modern societies require. The actual quality of government decision making can be higher if government permits substantial bureaucratic discretion. Granting such kind of discretion permits involving more substantive expertise and also permits implementation decisions to be linked more closely with the initial legislative intention about policy provided that the discretion is exercised in thoughtful and constructive manner. The capacity to link rule making with implementation also should be expected to enhance the overall quality of governance, for example an agency could respond quickly and flexibly to specific problems and is therefore necessary and desirable for effective implementation. It is virtually impossible for a rule-making body, whether legislative or administrative, to anticipate the range of variations (strategic instantiations) that may arise in the actual implementation of a program, so building in flexibility/adaptability is crucial. If major policy changes occur during the implementation stage of the policy process then there should be greater opportunity for involvement of not only the interest groups and experts who were there during public policy design but also should they be involved during policy change and implementation stages along with involving the public is becoming important as a part of displaying compliance to satisfy the democratic as well as utilitarian reasons. It is a kind of backward-mapping approach to implementation [26] when working for the scenario of implementation of e-government vis-à-vis viewing it as a true and ideal process of e-governance implementation approach.

Peter et al. (2004) [32] cited that from demand perspective, as a part of democratic process, citizens and businesses are finding it very hard to access relevant legislation, local procedures, rules, policy documents and a other policy and law making activities from different government bodies at different levels of public administration, including Local, regional and central. A commonly accepted requirement in this context is that online state legislative information should be equally made available and applicable to all [21].

Former UN Secretary-General Kofi Annan suggested that ICT should play significant role for the world to achieve the Millennium Development Goal in 2015. Ferro and Molinari (2010) [22] mentioned that (i) Lack of policy intelligence skills and the governance of ICT investments (ii) mere automation rather than innovation of processes and (iii) lack of citizen centricity and care for generating value to their livelihood process are the drawbacks in the current state of ICT investment and development [2]. Therefore it is important to focus on interoperability [1], semantic data integration [43] for achieving integrated view of multiple standards [45] as well as legal ontologies and application of semantic web-technologies to the legal domain [15] in terms of granularity (domain specific vs. core). The use of Semantic web technologies for web implementations in E-Governance will benefit end users as well as the decision makers in the government [31].

\section{REFERENCES}

[1] Al-Sudairi M A T \& Vasista, T G K (2011). "Semantic Data Integration Approaches". International Journal of Web \& Semantic Technology (IJWesT), 2(1), 1-12

[2] Al-Sudairi, M. A. T. \& Vasista, T. G. K. (2012) "Fostering Knowledge management and citizen participating in E-Governance for Achieving Sustainable Balanced Development”. The IUP Journal of Knowledge Management, X (1), 52-64.

[3] Al-Sudairi, M A T \& Vasista, T G K (2013) “Achieving Process Standardization in Digital Society with ASCP Model. Journal of Supply Chain \& Customer Relationship Management, Article ID 759359, 12 pages 
International Journal of Managing Public Sector Information and Communication Technologies (IJMPICT) Vol. 7, No. 2, June 2016

[4] Alessio Gugliotta (2006), Knowledge Modelling for Service-oriented applications in the e-Government Domain, Ph. D Thesis submitted to Dipartimento di Matematica e Informatica Universit`a degli Studi di Udine, Udine, Italy.

[5] Alkhatib, G. I. (2010). Web Engineering Advancements and Trends: Building New Dimensions of Information Technology. 374 pages, IGI Global Publishers.

[6] Apostolou, D., Mentzas, G., Stojanovic, L., Thoenssen, B., \& Pariente Lobo, T. (2011). “A collaborative decision framework for managing changes in e-Government services". Government Information Quarterly, 28(1), 101-116.

[7] ASCCC (n. d.). The Life cycle of legislation: From idea into law. [Online] URL: http://www.asccc.org/sites/default/files/the\%20life\%20cycle\%20of\%20legislation.pdf Retrieved on May 24, 2016

[8] BARBARA H. BRANDON, ROBERT D. CARLITZ $\square$, (2002), Online Rulemaking and Other Tools for Strengthening Our Civil Infrastructure, Members of Information Renaissance, USA.

[9] Bargui, F., Ben-Abdallah, H. and Feki, J. (2011). "A decision making ontology building process for analytical requirements elicitation". International Joint Conference of IEEE TrustComm-11. IEEE ICESS-11 and FCST-11, IEEE Computer Society.

[10] Bishop, P. and Davis, G. (2002).’Mapping public participation in policy choices”. Australian journal of public administration, 61(1), 14-29.

[11] Bogdanovskaia, I. (n.d.). The legislative bodies in the law-making process. [Online] URL: http://www.nato.int/acad/fellow/97-99/bogdanovskaia.pdf Retrieved on May 24, 2016.

[12] Brandon, B. H. And Carlitiz, R. D. (2002). "Online Rulemaking and other tools for strengthening our civil infrastructure". Administrative Law Review. 54(4), 1421-1422.

[13] Brusa, G., Caliusco, M.L. and Chiotti, O. (2006). "A Process for Building a Domain Ontology: an Experience in Developing a Government Budgetary Ontology". In M. A. Orgun, M. A. and T. Meyer, (Eds.) Proceeding of Second Australasian Ontology Workshop (AOW 2006), Hobart, Australia, 7-15.

[14] Brusa, G., Caliusco, M. L. and Chiotti, O. (2006). "Building ontology in public administration: A case study". In First International Workshop on Applications and Business Aspects of the Semantic Web SEBIZ, Athens, Georgia, USA. URL: ftp.informatik.rwth-aachen.de/Publications/CEURWS/Vol-226/paper02.pdf, Retrieved on April 24, 2009.

[15] Casanovas,P., Sartor,G. \& Biasiotti, A. \& Fernandez-Barrera, M. (2011). "Chapter 1 Introduction: Theory and Methodology in Legal Ontology Engineering: Experiences and Future Directions". In G. Sartor, P. Cananovas, M. A. Biasiotti \& M. Fernandez-Barrera (Ed.). Approaches to Legal Ontologies: Theories, Domains, Methodologies, Springer.

[16] Cathia Glibert Riley (2003), The changing role of citizen in the E-Governance and E-Democracy Equation, Common Wealth Centre for E-Governance.

[17] Conen, A. (n. d.). An SOA case study: Agility in practice. [Online] URL: http://searchsoa.techtarget.com/tip/An-SOA-case-study-Agility-in-practice Retrieved on May 23, 2016.

[18] Cunningham, A. (Undated). The Uses of Metadata in Public Administration: digital preservation Europe-briefing

http://www.digitalpreservationeurope.eu/publications/briefs/uses_of metadata in public_administr ation.pdf (Accessed on September 3, 2013).

[19] Davies, John (2006). Semantic Web Technologies: Trends and Research in Ontology-based Systems. Wiley, 2006. ISBN 0470025964.

[20] Day, Michael (2005). "Metadata". In DCC Digital Curation Manual". [Online] URL: https://www.era.lib.ed.ac.uk/bitstream/handle/1842/3321/Day\%20metadata.pdf?sequence=1 Retrieved on May 23, 2016.

[21] Fagan, J. C. and Fagan, B. (2004). "An accessibility study of state legislative web sites". Government Information Quarterly, 21, 65-85.

[22] Ferro, E. and Molinari, F.(2010). "Making sense of Gov 2.0 Strategies: No Citizens No Party", JeDEM - eJournal of eDemocracy and Open Government, 2(1), 56-68.

[23] Glance, N., Hurst, M., Nigam, K., Siegler, M., Stockton, R., and Tomokiyo,T. (2005), "Deriving Marketing Intelligence from Online Discussion", Proceedings of the 11th international conference on knowledge discovery in data mining, ACM SIGKDD, 419-428. 
[24] Gugliotta, A. (2006). Knowledge Modelling for Service-oriented applications in the e-Government Domain, A Ph. D Thesis submitted at the Dipartimento di Matematica e Informatica Universit'a degli Studi di Udine, Udine, Italy.

[25] HCIO (2010). Parliamentary stages of a Government Bill. Factsheet L1 Legislation Series, House of Common Information Office, UK. [Online] URL: https://www.parliament.uk/documents/commons-information-office/101.pdf Retrieved on May 24, 2016.

[26] Hunold, C. and Peters, G. (2008). "Bureaucratic Discretion and Deliberative Democracy". In A. Ari-Veikko (Ed.) Electronic Government: Concepts, Methodologies, Tools and Applications, USA: Information Science Reference (An Imprint of IGI Global).

[27] Janssen, D. and Kies, R. (2005). “Online forums and deliberate democracy”. Acta politica, 40 (3). 317-335.

[28] Javalgi, R. G., Martin, C. L., and Todd, P. R. (2004). "The export of e-services in the age of technology transformation: challenges and implications for international service providers". Journal of Services Marketing, 18(7), 560-573.

[29] Joanne, E., Reed, B. and McKemmish, S. (2008). "Interoperable Data: Sustainable Frameworks for Creating and Managing Recordkeeping Metadata", Records Management Bulletin, 18(2), 115-129.

[30] Loukis, E., Wimmer, M. A., Charalabidis, Y., Triantafillou, A., and Gatautis, R. (2007, September). "Argumentation systems and ontologies for enhancing public participation in the legislation process". In EGOV 2007 international conference, 3-7.

[31] Mampilli, B. S., and Meenakumari, J. (2012). "A Study on Enhancing E-Governance Applications through Semantic Web Technologies"., 1(2), 53-59

[32] Peters, R.M., Janssen M., van Engers T. M. (2004). "Measuring e-government impact: existing practices and shortcomings", March 2004 ICEC '04: Proceedings of the 6th International conference on Electronic Commerce. International Journal of Web Technology

[33] PREMIS (PREservation Metadata: Implementation Strategies) Working Group, Data Dictionary for Preservation Metadata: Final Report of the PREMIS Working Group, May 2005 (United States of America) http://www.oclc.org/research/projects/pmwg/pre mis-final.pdf Retrieved during 2009

[34] Purpura, S., Cardie, C. and Simons, J. (2008). "Active learning for e-rulemaking: public comment categorization". Proceedings of international conference on digital government research, 234-243.

[35] Riley, C. G. (2003). The changing role of citizen in the E-Governance and E-Democracy Equation, Common Wealth Contre E-Governance, http://www.tanzaniagateway.org/docs/Changing_role_of_the_citizen_in_the_E-governance_Edemocracy_equation_2003.pdf (Accessed on September 3, 2013).

[36] Roman, D., Keller, Uwe, Lausen, H., de Brujjn, J., Lara, R., Stollberg, M., Polleres, Feier, C., Bussler, C. \& Fensel, D. (2005). Web Service Modeling Ontology, DERI, Austria \& Ireland. [Online] URL: http://uwekeller.mydomain.com/publications/ao2005.pdf Retrieved on May 23, 2016

[37] Sicillia, M-A. (2014). A-<A>: Handbook Metadata, Semantics and Ontologies. [Online] URL: http://file.allitebooks.com/20150731/Handbook\%20of\%20Metadata,\%20Semantics\%20and\%20Ont ologies.pdf Retrieved on May 23, 2016.

[38] Stamoulis, D, Gouscos, D, Georgiadis, P. and Martakos, D. (2001). "Revisiting public information management for effective e-government services". Information Management \& Computer Security, 9(4), $146-153$

[39] Stojanovic, L., Kavadias, G., Apstolou, D., Probst, F. and Hinkelmann, K. (2004). "D2: E-Gov Service Lifecycle Ontology", IST PROJECT 507237, http://userpages.unikoblenz.de/ egov/wiki/images/OntoGovOntology.pdf (Accessed on September 3, 2013).

[40] Tambouris, Efthimios and Konstantinos Tarabanis (2004), 'An Overview of DC-Based e-Government Metadata Standards and Initiatives', Lecture Notes in Computer Science, Springer, Berlin, 40-47.

[41] Trajkova, J. and Gauch, S. (2004), "Improving Ontology-Based User Profiles", Electrical Engineering and Computer Science, University of Kansas, USA

[42] Trampus, M., Sen, S., Stojanovic, N. and Grobelnik, M. (2012). "Chapter 9: Visualisation of Online Discussion Forums". In Y. Charalabidis and S. Koussouris (eds.), Empowering Open and Collaborative Governance, 157-179, Springer Berlin Heidelberg. 
International Journal of Managing Public Sector Information and Communication Technologies (IJMPICT) Vol. 7, No. 2, June 2016

[43] Vasista, T G K \& AlSudairi, M A T (2013). "Service-Oriented Architecture (SOA) and Semantic Web Services for Web Portal Integration". In Meghanathan (Ed.) Advances in Intelligent Systems and Computing, 177, 253-261. Springer

[44] Vlad Tanasescu (2005). An Ontology-Driven Life-Event Portal. Master thesis submitted to EPFLLSIR Open University, France.

[45] Wong, A., Yip, F., Ray, P. \& Paramesh, N.(2008). “Towards semantic interoperability for IT Governance: An Ontological Approach". Computing and Informatics, 27, 131-155.

[46] Yee, G. and Korba, L. (2004). "Privacy policy compliance for Web services". IEEE International Conference on Web Services, July 6-9, San Diego, CA, USA, 158-165.

\section{Other references $[\mathrm{OR}]$}

[1] There are also sections devoted to the OAIS model, preservation metadata, standards and package formats such as METS. [OR, 1]

[2] http://www.dcc.ac.uk/resource/curationmanual/chapters/metadata/ [OR, 2]

[3] Dublin Core Metadata Initiative http://www.dublincore.org/ [OR, 3]

[4] Dublin Core Metadata Initiative Glossary [OR, 4]

[5] http://www.dublincore.org/documents/usageguide/glossary.shtml [OR, 5]

[6] Introduction to Ontologies and the Semantic Web, http://obitko.com/tutorials/ontologiessemanticweb/ [OR, 6]

[7] Electronic Records Management and Archives Management Policy. http://www2.arkib.gov.my/borang/guideline_eng.pdf [OR, 7]

\section{Author}

Dr. TGK Vasista is currently a freelance e-Governance Consultant and works as an adjunct faculty in engineering colleges in India. He obtained a Doctorate in Information Technology from Commonwealth of Dominica, West Indies, a PostGraduate Diploma in E-Governance from India, an MBA in E-Business from USA and a Master of Engineering in Civil Computer Aided Design from India. He has former experiences in the field of IT as a programmer analyst in USA and as a senior Lecturer/Asst. Professor in academic field in the area of Systems and IT, EGovernance, E-Business and Project Management. His interested areas include: EGovernance, Enterprise Systems and Construction \& Project Management. He has about 60+ publications related to E-business, E-governance and Project Management overall, which include some in refereed journals, international and national conferences. He received a best paper award in a National IT conference in 2007 in India. He has about 60 citations for his published papers $\mathrm{He}$ is an editor reviewer to journals at AIRCC publications. He is recently awarded as one of the Excellent Constructive Reviewers at IBIMA $27^{\text {th }}$ Conference held in Milan, Italy during May 4-5, 2016.

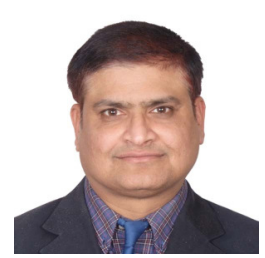

